\title{
Sistem Pakar Diagnosa Hama Penyakit Tanaman Padi Dan Holtikultura Menggunakan Metode Forward Chaining Berbasis Android
}

\author{
Frengki Pernando ${ }^{1}$, Ahmad Fauzi ${ }^{2}$ \\ ${ }^{1}$ STMIK NUSAMANDIRI JAKARTA \\ e-mail: 14002136@nusamandiri.ac.id \\ ${ }^{2}$ STMIK NUSAMANDIRI JAKARTA \\ e-mail: demore.band@gmail.com
}

\begin{abstract}
The development of information and communication technology-based smartphones and mobilephone growing rapidly. It is characterized by the number of smartphone users in the community. Utilization of information and communication technology is implemented in the form of knowledge application. One of these applications on the world agricultural expert system based on mobile. Knowledge of this expert system has many sources including research or research and observations that have been practiced by experts and issued either through web resources and other sources such as agricultural books, journals and others. This expert system uses Forward Chaining method using base database organized into a table in a rule that an expert and user can draw conclusions from what has been diagnosed by this expert system. Application of expert system designed and developed as an expert tools and users in diagnosing pests and diseases of rice plants and horticulture of the analysis by an expert and analysis according to the book or internet media. This expert system will show the questions will then be selected by the user to find a solution on the diagnostics program that has been done on this expert system. In addition the expert system is equipped with the paperwork to determine how plant pest management, plant species and type of fertilizer.
\end{abstract}

Keywords: Expert System, Plants of Pests, Forward Chaining.

\section{PENDAHULUAN}

Seiring berkembangnya kemajuan teknologi smartphone saat ini, sistem operasi yang digunakan pada smartphone semakin berkembang, beberapa diantaranya yaitu Android, RIM Blackberry, Microsoft Windows Mobile, dan Symbian. Dengan diterapkannya sistem operasi pada smartphone, menjadikan smartphone sebagai salah satu perangkat mobile yang dapat menggantikan $P C$ dalam beberapa hal. Sistem operasi Android mempunyai beberapa kelebihan dibandingkan dengan sistem operasi pada telepon genggam yang lainnya, yaitu Android bersifat open source, multitasking, dan juga memberi kemudahan-kemudahan dalam pengembangan aplikasi berbasis Android karena tersedianya dokumentasi, serta Android dikembangkan oleh perusahaan besar Google yang menyediakan fitur-fitur layanan Google (Santoso \& Rais, 2015).

Dalam dunia pertanian, tanaman padi mempunyai arti penting dalam kehidupan manusia karena menjadi tanaman penghasil beras yang merupakan bahan makanan pokok sebagian besar masyarakat Indonesia. Begitu juga dengan tanaman holtikultura yang menjadi tanaman penghasil sayuran, buahbuahan dan obat-obatan. Semakin meningkatnya populasi manusia maka kebutuhan akan beras, sayuran, buah-buahan semakin meningkat. Untuk meningkatan hasil pertanian tersebut diperlukan upaya-upaya antara lain dengan cara pembukaan lahan baru, perbaikan infrastruktur, peningkatan kualitas benih serta pengendalian hama dan penyakit yang bisa menyerang tanaman padi maupun tanaman holtikultura. Pengendalian hama dan penyakit pada tanaman padi dan tanaman holtikultura memerlukan pengetahuan yang luas dan penanganan khusus agar tidak terjadi dampak negatif pada ekosistem dan lingkungan. Penanggulangan dapat dilakukan dengan mengenali gajala-gejala yang terjadi pada tanaman tersebut. Karena kurangnya pengetahuan dan penanggulangan petani terhadap hama dan penyakit tanaman maka sering terjadi gagal panen. Dalam menghadapi persoalan tersebut maka perlu diadakan penyuluhan-penyuluhan oleh ahli atau pakar pertanian untuk menganalisa faktor-faktor atau gejala-gejala awal dan mengindentifikasi jenis penyakit pada tanaman tersebut. Akan tetapi, terbatasnya sumber daya manusia pakar pertanian dan masih banyak penyuluh pertanian yang belum 
mempunyai pengetahuan yang memadai untuk bisa menggantikan fungsi sebagai seorang pakar menjadi kendala yang masih banyak terjadi dilapangan. Selain itu, karena data-data penyuluhan yang belum tersimpan dalam sistem terkomputerisasi maupun aplikasi mobile juga menjadi penghambat masyarakat yang bertanya tentang hama dan penyakit pada tanaman padi dan holtikultura. Hal ini sangat menyita waktu sehingga tidak efisien dalam mengatasi permasalahan pertanian. Untuk membantu mengatasi hal tersebut.

Berdasarkan permasalahan tersebut maka untuk membantu para petani dibutuhkan pemanfaatan teknologi informasi dengan sistem pakar metode Forward Chaining.

\section{METODOLOGI PENELITIAN}

Dalam penelitian ini dibagi menjadi beberapa tahapan, diantaranya yaitu: observasi, wawancara,studi pustaka.

Pada tahapan pertama adalah tahap observasi, yaitu pengumpulan data dengan mengamati secara langsung atau mendiagnosis hama dan penyakit pada tanaman padi dan holtikultura pada Laboratorium Pengamatan Hama Penyakit Tanaman Banyumas. Yang beralamat di Kompleks UPP Tajum Tinggarjaya Kecamatan Jatilawang Banyumas 53174. Tahap kedua adalah wawancara, pada tahapan ini dikulakuakn identifikasi masalah dengan cara mewawancarai mengajukan beberapa pertanyaan seputar program yang dibuat kepada seorang pakar yaitu bapak Aries Pratomo, SP., M.Sc. Tahapan terakhir adalah studi pustaka mengumpulkan data dengan mengadakan studi penelaahan terhadap buku-buku, literatur-literatur, catatan-catatan, dan laporan-laporan yang berhubungan dengan hama dan penyakit pada tanaman padi dan tanaman holtikultura.

Sistem pakar merupakan program komputer untuk dapat meniru proses pemikiran dan pengetahuan pakar untuk menyelesaikan suatu masalah yang spesifik. Implementasi sistem pakar banyak digunakan untuk kepentingan masyarakat karena sistem pakar dipandang sebagai cara penyimpanan pengetahuan pakar dalam bidang tertentu ke dalam suatu program, sehingga dapat memberikan keputusan dan melakukan penalaran secara cerdas. Sistem pakar merupakan cabang dari kecerdasan buatan dan juga merupakan bidang ilmu yang muncul seiring perkembangan ilmu komputer saat ini. Sistem ini bekerja untuk mengadopsi pengetahuan manusia ke komputer yang menghubungkan dasar pengetahuan dengan sistem inferensi untuk menggantikan fungsi seorang pakar dalam menyelesaikan suatu masalah (Amanda \& Mustafidah, 2011).
Sistem pakar adalah sistem komputer yang ditujukan untuk meniru semua aspek (emulate) kemampuan pengambilan keputusan (decision making) seorang pakar. (Rosnelly, 2012)

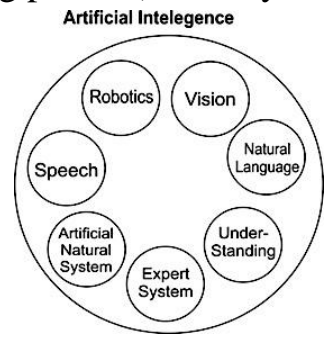

Gambar 1. Area dari Artificial Intelligence (AI)

(Rosnelly, 2012)

komponen utama pada struktur sistem pakar meliputi Basis Pengetahuan / Knowledge Base, Mesin Inferensi / Inference Engine, Working Memory, dan Antarmuka Pemakai / User Interface. Struktur sistem pakar dapat ditunjukkan pada Gambar 2(Durkin,1994).

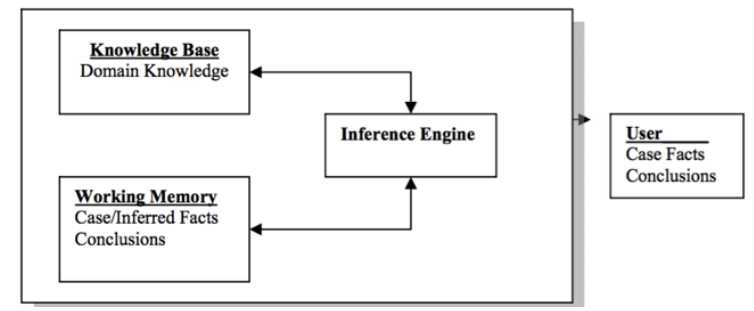

Gambar 2. Struktur Sistem Pakar (Durkin,1994)

Sedangkan untuk metode sistem pakar yang digunakan dengan forward chaining adalah pencocokan fakta atau pernyataan dimulai dari sebelah kiri (IF dulu). Dengan kata lain, penalaran dimulai dari fakta terlebih dahulu untuk menguji kebenaran hipotesis [Kusumadewi dalam Azhar dkk, 2014]. Penalaran ini berdasarkan fakta yang ada (data driven), metode ini adalah kebalikan metode Backward Chaining, dimana metode ini dijalankan dengan mengumpulkan fakta-fakta yang ada untuk menarik kesimpulan. Dengan katalain, prosesnya dimulai dari facts (fakta-fakta yang ada) melalui proses interface fact (penalaran fakta fakta) menuju suatu goal (suatu tujuan) (Pratama \& Setiyadi, 2018).

Secara umum dalam inferensi penalaran maju (Forward Chaining) aturan (rule) akan diuji satu persatu dalam urutan tertentu. Saat tiap aturan diuji, sistem akan mengevaluasi apakah kondisi benar atau salah. Dengan kata lain, penalaran dimulai dari fakta terlebih dahulu untuk menguji hipotesis. Forward chaining adalah data- driven karena inferensi 
dimulai dengan informasi yang tersedia dan kemudian konklusi akan diperoleh (Aribowo \& Khomsah, 2011)

Forward Chaining adalah metode pencarian / penarikan kesimpulan yang berdasarkan pada data atau fakta yang ada menuju ke kesimpulan, penelusuran dimulai dari fakta yang ada lalu bergerak maju melalui premis-premis untuk menuju ke kesimpulan / bottom up reasoning. Forward chaining melakukan pencarian dari suatu masalah kepada solusinya. Jika klausa premis sesuai dengan situasi, maka proses akan memberikan kesimpulan (Ayu, Tutik, Delima, \& Proboyekti, 2009). Pada gambar 3 diilustrasikan gambaran kerja forward chaining.

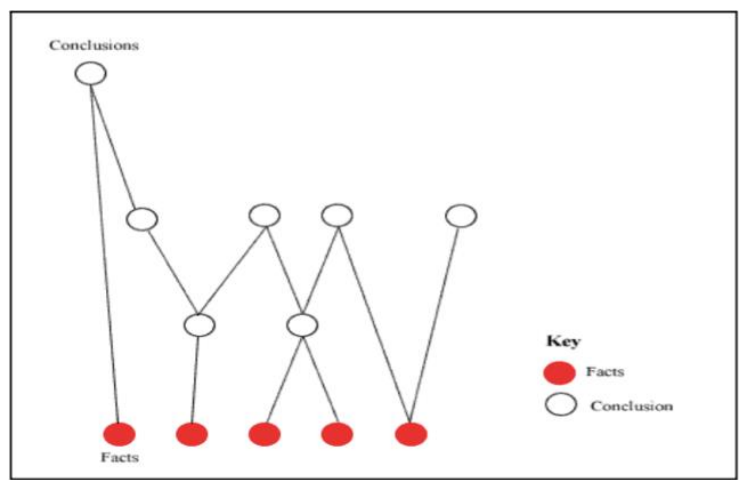

Gambar 3. Gambaran kerja Forward chaining / Bottom Up Reasoning (Ayu et al., 2009)

Bentuk representasi Rule Based Reasoning digunakan karena memiliki sejumlah pengetahuan pakar pada suatu permasalahan tertentu dan pakar dapat menyelesaikan masalah tersebut secara sistematis dan berurutan. Representasi berbasis aturan yang mempunyai pola if kondisi/premis then aksi/konklusi pada suatu tabel pakar akan memberikan keuntungan pada berbagai aspek, diantaranya mudah dalam memodifikasi, baik perubahan data, penambahan data atau penghapusan data. Dalam hal ini if bisa direprentasikan sebagai gejala-gejala yang dirasakan saat mengendarai mobil dan then berupa solusi-solusi yang dicapai (Wele \& Mulyanto, n.d.)

\section{HASIL DAN PEMBAHASAN}

Berikut ini adalah pembahasan rancangan sistem pakar diagnosa penyakit tanaman padi dan holtikultura.

1. Perancangan Database

Dalam aplikasi mobile berbasis android ini, menggunakan table database sebagai penyimpanan informasi, yaitu :

a. Tabel database login
Tabel III.1

Database Login

\begin{tabular}{|c|c|c|c|c|c|}
\hline \multirow[t]{2}{*}{ No } & Elemen & Akronim & & Panjang & Keterangan \\
\hline & \multicolumn{2}{|l|}{ Data } & \multicolumn{3}{|l|}{ Tipe } \\
\hline 1 & Nama & Nama & Text & 30 & Nama user \\
\hline 2 & Email & Email & Text & 30 & Email user \\
\hline \multirow[t]{2}{*}{3} & Username & Username & Text & 10 & Nama user \\
\hline & & & & & $\operatorname{login}$ \\
\hline 4 & Password & Password & Text & 10 & password \\
\hline
\end{tabular}

b. Tabel database gejala

Tabel III. 2

Tabel Database Gejala

\begin{tabular}{|c|c|c|c|c|c|}
\hline $\begin{array}{l}\mathrm{N} \\
\mathrm{o}\end{array}$ & $\begin{array}{l}\text { Elemen } \\
\text { Data }\end{array}$ & Akronim & Tipe & Panjang & Keterangan \\
\hline 1 & $\begin{array}{l}\text { Kd_gejal } \\
\text { a }\end{array}$ & Kd_gejala & Text & 5 & $\begin{array}{l}\text { Primary } \\
\text { Key }\end{array}$ \\
\hline 2 & $\begin{array}{l}\text { Pertanya } \\
\text { an }\end{array}$ & Pertanyaan & Text & 200 & \\
\hline 3 & $\begin{array}{l}\text { Fakta } \\
\text { YA }\end{array}$ & FaktaYa & Text & 200 & \\
\hline 4 & $\begin{array}{l}\text { Fakta } \\
\text { TIDAK }\end{array}$ & $\begin{array}{l}\text { FaktaTID } \\
\text { AK }\end{array}$ & Text & 200 & \\
\hline 5 & $\mathrm{Ya}$ & $\mathrm{Ya}$ & Text & 5 & \\
\hline 6 & Tidak & Tidak & Text & 5 & \\
\hline
\end{tabular}

c. Tabel database hama dan penyakit

Tabel III.3.

Tabel Database Penyakit

\begin{tabular}{|c|c|c|c|c|c|}
\hline $\begin{array}{l}\mathrm{N} \\
\mathrm{O}\end{array}$ & Elemen Data & Akronim & Tipe & $\begin{array}{l}\mathrm{Pa} \\
\text { nja } \\
\text { ng }\end{array}$ & $\begin{array}{l}\text { Keterang } \\
\text { an }\end{array}$ \\
\hline 1 & $\begin{array}{c}\text { Kode_Tanam } \\
\text { an }\end{array}$ & $\begin{array}{c}\text { Kd_Tanam } \\
\text { an }\end{array}$ & Text & 5 & $\begin{array}{l}\text { Primary } \\
\text { Key }\end{array}$ \\
\hline 2 & $\begin{array}{c}\text { Kode_Penyak } \\
\text { it }\end{array}$ & $\begin{array}{c}\text { Kd_Penyak } \\
\text { it }\end{array}$ & Text & 5 & \\
\hline 3 & Kode_Hama & Kd_Hama & Text & 5 & \\
\hline 4 & $\begin{array}{c}\text { Nama_Tana } \\
\text { man }\end{array}$ & $\begin{array}{c}\text { Nm_Tanam } \\
\text { an }\end{array}$ & Text & 50 & \\
\hline 5 & $\begin{array}{c}\text { Nama_Penya } \\
\text { kit }\end{array}$ & $\begin{array}{c}\text { Nm_Penya } \\
\text { kit }\end{array}$ & Text & 50 & \\
\hline 6 & Nama_Hama & Nm_Hama & Text & 50 & \\
\hline
\end{tabular}

d. Tabel database Solusi

Tabel III. 4

Tabel Database Solusi

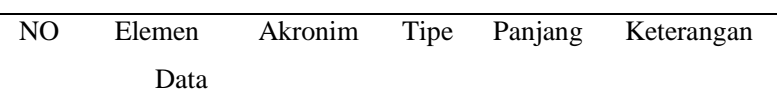




\begin{tabular}{llllll}
\hline 1 & ID & ID_solusi & Text & 5 & $\begin{array}{l}\text { Primary } \\
\text { Key }\end{array}$ \\
\hline 2 & Solusi & Solusi & Text & 2000 & \\
\hline
\end{tabular}

2. Heirrachy Input Proccess Output

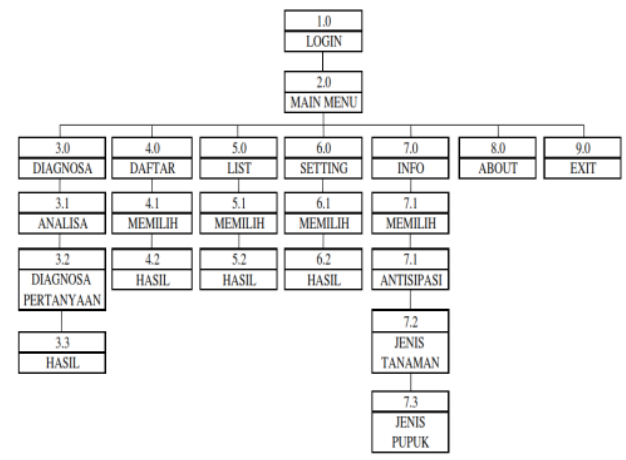

3. Flowchart

Gambar 4. HIPO

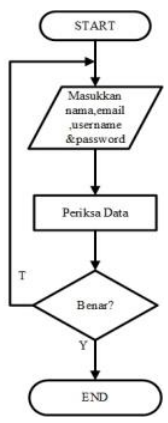

Gambar 5. Flowchart login user

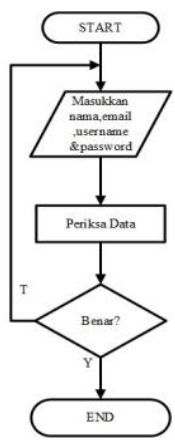

Gambar 6. Flowchart Sign Up

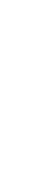

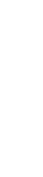

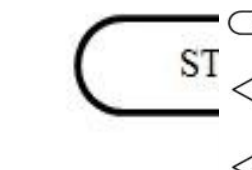

T<smiles>CC(C)C1CCCC1CO</smiles>

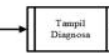
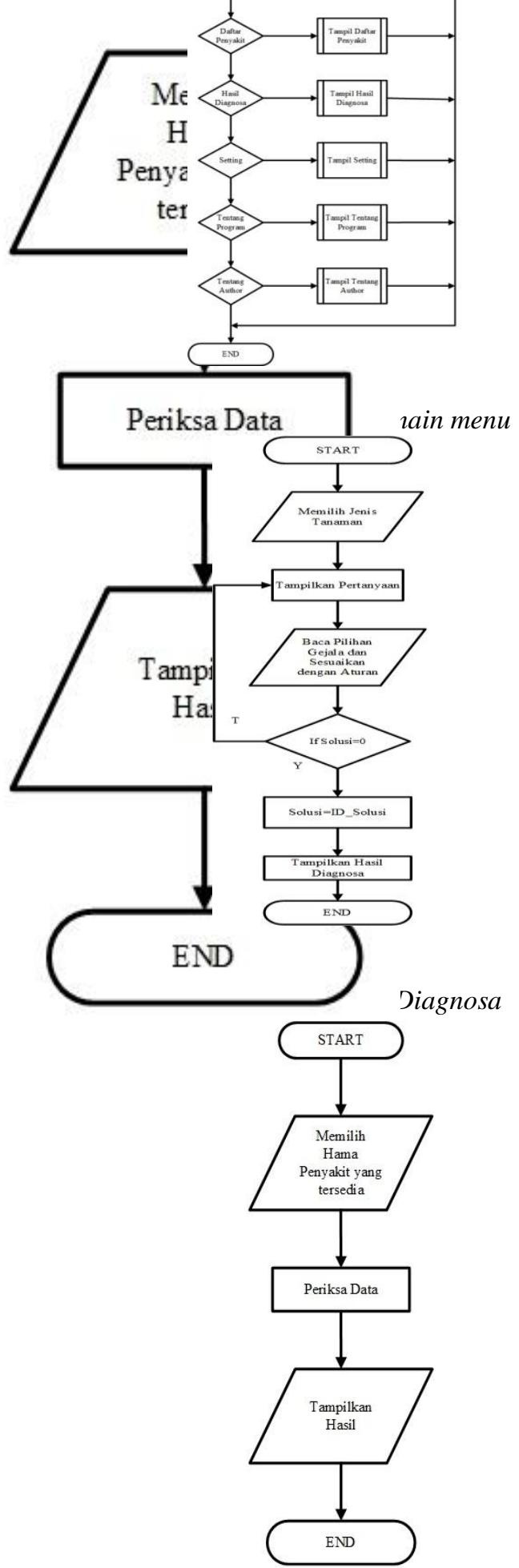

Gambar 9. Flowchart daftar Penyakit 


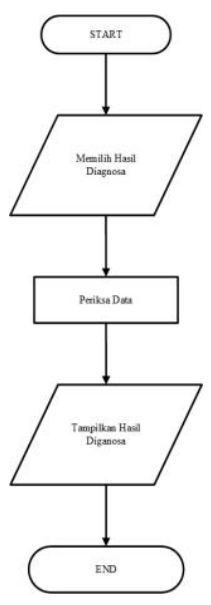

Gambar 10. Flowchart Hasil Diagnosa

4. Deployment Diagram

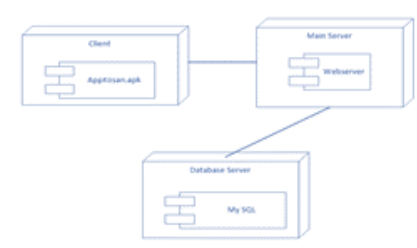

Gambar 11. Deployment program

5. User Interface

a. Tampilan menu Login

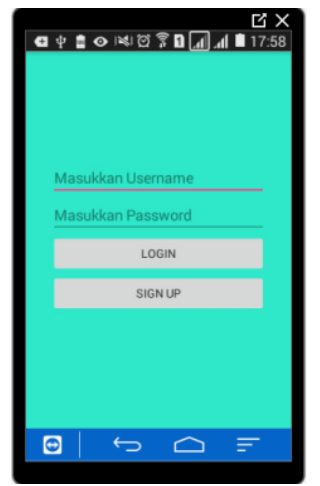

Gambar 11. Login

b. Tampilan menu Sign Up

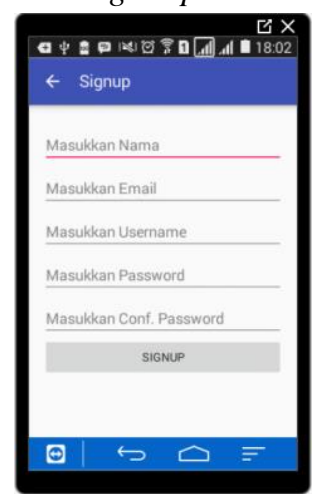

Gambar 12. Sign Up c. Tampilan Layout Diagnosa

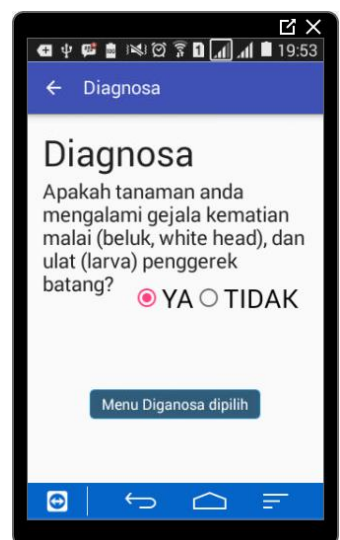

Gambar 13. Layout Diagnosa

d. Tampilan Layout Daftar Penyakit

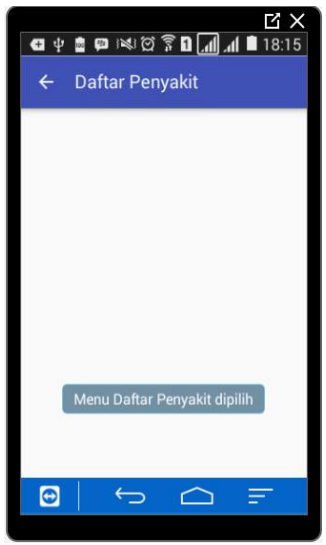

Gambar 14. Daftar Penyakit

e. Tampilan layout hasil diagnosa

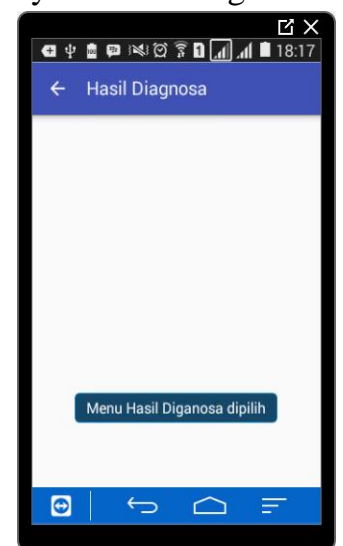

Gambar 15. Hasil Diagnosa 
f. Tampilan Layout Setting

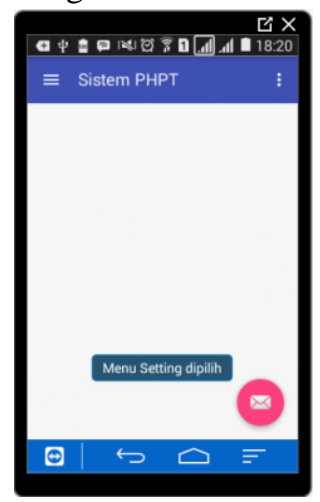

Gambar 16. Setting

g. Tampilan layout hasil setting

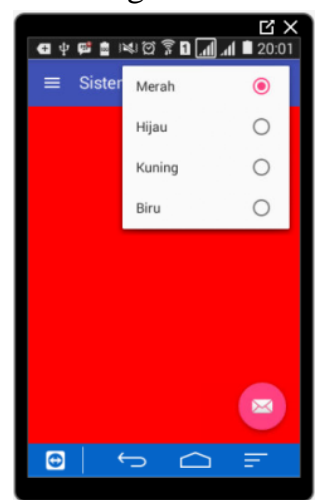

Gambar 17. Hasil Setting

h. Tampilan Layout tentang Program

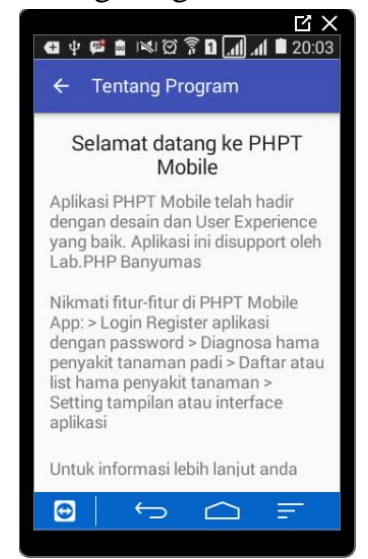

Gambar 18. Tentang Program

\section{Support}

Dalam menjalankan aplikasi sistem pakar ini dibutuhkan perangkat yang mendukung sistem operasi android dengan kriteria OS minimal versi Marshmallow 6.0, prosesor dan memori ramnya harus cukup besar.

\section{KESIMPULAN}

Pada Aplikasi sistem pakar ini dapat membantu masyarakat umum dalam mengidentifikasi jenis hama penyakit tanaman padi dan holtikultura berbasis mobile aplication android. Pengetahuan tentang hama penyakit padi dapat di informasikan secara mobile dapat membantu seorang pakar dalam melaksanakan tugasnya secara lebih efisien.

\section{REFERENSI}

Abdulloh, Syukri. (2012, Maret 27). Program Komputer. Dipetik Juni 20, 2016, dari http://www.itartikel.com: http://www.itartikel.com/2012/03/program-komputer.html

Baru, Jadi. (2015, November 9). Android Studio. Dipetik Juni 2016, 20, dari http://www.jadibaru.com/:

http://www.jadibaru.com/android/pengenalanandroid-studio-2/

Browser, SQLite. (t.thn.). DB For SQLite. Dipetik Juni 20, 2016, dari http://sqlitebrowser.org/: http://sqlitebrowser.org/

C, Antonius. Rachmat. (2010). Algoritma dan Pemrograman dengan Bahasa C-Konsep, Teori \& Implmentasi. Yogyakarta: Andi Offset.

Developer, Android. (t.thn.). Meet Android Studio. Dipetik Juni 20, 2016, dari https://developer.android.com: https://developer.android.com/studio/intro/index.htm 1

EP, Fajar. Jaenudi. (2007). Algoritma dan Pemrograman. Jakarta: Salemba Infotek.

Fatta, Hanif. Al. (2007). Analisa dan Perancangan Sistem Informasi untuk Keunggulan Bersaing Perusahaan dan Organisasi Modern. Yogyakarta: Andi Offset.

Kusnadi. (2008). Sistem Operasi. Yogyakarta: Andi Offset.

Rosnelly, Rika. (2012). Sistem Pakar Konsep dan Teori. Yogyakarta: Andi Offset.

S, Stephanus. Hermawan. (2011). Mudah Membuat Aplikasi Android. Yogyakarta: Andi Offset.

Suarga. (2012). Algoritma Pemrograman. Yogyakarta: Andi Offset.

Subari, Tata. (2012). Analisa Sistem Informasi. Yogyakarta: Andi Offset.

\section{PROFIL PENULIS}

1. Frengki Pernando

Lahir di Cilacap 29 Mei 1995 , berpendidikan terakhir meraih gelar Sarjana Komputer pada tahun 2017 di Program STMIK Nusamandiri Jakarta dan sedang melanjutkan studi Pasca Sarjana Ilmu Komputer, bekerja sebagai Instruktur Komputer pada Program Studi Sistem Informasi STMIK Nusamandiri jakarta.

2. Ahmad Fauzi

Lahir di Bekasi 4 April 1990, berpendidikan terakhir meraih gelar Master Komputer pada tahun 2016 di Program Pasca Sarjana STMIK Nusamandiri Jakarta dan bekerja sebagai Dosen Program Studi Sistem Informasi STMIK Nusamandiri jakarta. 